\title{
Perbandingan Intensitas Nyeri dan Kadar Prostaglandin Kombinasi Tramadol dan Deksketoprofen dengan Tramadol dan Parasetamol Intravena pada Pasien Bedah Ortopedi Ekstremitas Bawah
}

\author{
Clara Valentia Josephine, Muh. Ramli Ahmad, Hisbullah, Abdul Wahab \\ Departemen Ilmu Anestesi dan Terapi Intensif \\ Fakultas Kedokteran Universitas Hasanuddin/RSUP Dr. Wahidin Sudirohusodo Makassar
}

\begin{abstract}
Abstrak
Analgesia multimodal adalah prinsip manajemen nyeri pascaoperasi. Penelitian ini merupakan uji klinis rancangan acak tersamar ganda. Tujuan penelitian ini membandingkan efek kombinasi analgesik tramadol dan deksketoprofen dengan tramadol dan parasetamol terhadap intensitas nyeri dan kadar prostaglandin $\left(\mathrm{PGE}_{2}\right)$ di RSUP Dr. Wahidin Sudirohusodo serta Rumah Sakit Jejaring di Makassar pada bulan JuliSeptember 2018. Empat puluh enam pasien ASA PS I dan II yang menjalani operasi ortopedi ekstremitas bawah dibagi menjadi dua kelompok. Kelompok D adalah pasien yang menerima $50 \mathrm{mg}$ tramadol dengan $50 \mathrm{mg}$ deksketoprofen dan kelompok P adalah pasien yang menerima $50 \mathrm{mg}$ tramadol dengan $1.000 \mathrm{mg}$ parasetamol intravena. $\mathrm{PGE}_{2}$ dan intensitas nyeri dicatat selama penutupan kulit sebelum pemberian obat 8 dan 16 jam sesudahnya. Data dianalisis menggunakan Uji Mann-Whitney U dan paired t-test yang sesuai. Numeric rating scale (NRS) kelompok tramadol dan deksketoprofen lebih rendah dibanding dengan kelompok tramadol dan parasetamol dengan perbedaan bermakna $(\mathrm{p}<0,05)$. Kadar $\mathrm{PGE}_{2}$ menurun pada kelompok tramadol dan deksketoprofen (T1-T2 $\mathrm{p}=0,009$ dan T0-T2 $\mathrm{p}=0,01$ ), sedangkan kadar $\mathrm{PGE}_{2}$ pada kelompok tramadol dan parasetamol meningkat (T2-T1 p=0,227 dan T0-T2 $\mathrm{p}=0,706$ ). Simpulan, kombinasi tramadol dan deksketoprofen mengurangi tingkat $\mathrm{PGE}_{2}$ dan intensitas nyeri dibanding dengan kombinasi tramadol dan parasetamol.
\end{abstract}

Kata kunci: Deksketoprofen, parasetamol, $\mathrm{PGE}_{2}$, tramadol

\section{Comparison of Pain Intensity and Prostaglandin Level between Tramadol Dexketoprofen Combination and Tramadol Paracetamol Combination in Lower Limb Orthopedic Surgery}

\begin{abstract}
Multimodal analgesia is one of the principles of postoperative pain management. This study aimed to compare the effect of analgesic combination of tramadol dexketoprofen and tramadol paracetamol on pain intensity and prostaglandin ( $\mathrm{PGE}_{2}$ ) level. Forty-six ASA PS I and II patients undergoing lower limb orthopedic surgery were allocated into two groups. Group D received $50 \mathrm{mg}$ tramadol with $50 \mathrm{mg}$ dexketoprofen and group $P$ received $50 \mathrm{mg}$ tramadol with $1,000 \mathrm{mg}$ paracetamol intravenously. The $\mathrm{PGE}_{2}$ and pain intensity were recorded during skin closure prior to drug administration, 8 and 16 hours afterwards. Data were analyzed as appropriate using Mann-Whitney U and paired t-test. The NRS of two groups were significantly different where the NRS of the Tramadol Dexketoprofen group was lower than that of the tramadol and paracetamol group (NRS T1 p=0.049, NRS T2 p=0.035). The PGE ${ }_{2}$ levels decreased in the tramadol dexketoprofen groups (T1-T2 p=0.009 and T0-T2 p=0.01), whereas PGE ${ }_{2}$ levels in tramadol paracetamol group increased (T2-T1 $\mathrm{p}=0.227$ and T0-T2 $\mathrm{p}=0.706$ ). In conclusion, tramadol dexketoprofen combination reduces the PGE level $^{2}$ and pain intensity as opposed to tramadol paracetamol combination.
\end{abstract}

Key words: Dexketoprofen, paracetamol, $\mathrm{PGE}_{2}$, tramadol

Korespondensi: Clara Valentia Josephine, dr., Departemen Ilmu Anestesi dan Terapi Intensif Fakultas Kedokteran Universitas Hasanuddin Makassar, RSUP Dr. Wahidin Sudirohusodo, Jl. Perintis Kemerdekaan KM 11, Tamanlarea, Makassar, 90245, Tlp (0411) 84675, Email: sweet_cvj@yahoo.com 


\section{Pendahuluan}

Nyeri merupakan permasalahan penting yang dihadapi pada pasien pascabedah. Nyeri pascabedah akan memengaruhi sistem kardiovaskular, respirasi, dan endokrin yang berhubungan dengan komplikasi pascabedah. Kontrol nyeri pascabedah yang baik dihubungkan dengan tingkat morbiditas dan mortalitas yang lebih rendah serta waktu rawat inap yang lebih singkat sehingga mengurangi biaya rerata. ${ }^{1,2}$

Analgesia preventif yang mencakup terapi analgesia multimodal sebelum dan pascabedah bertujuan menurunkan nyeri dan mengurangi konsumsi analgesia pascabedah. Penggunaan obat-obat dan teknik anestesi yang bekerja pada proses sensitisasi sentral dan perifer dalam konsep Preventive Multimodal Analgesia menjadi pedoman penanganan nyeri pascabedah saat ini. Penanganan multimodal analgesia dapat dilakukan berdasar atas intensitas nyeri yang mungkin timbul akibat pembedahan yang dibagi berdasar atas intensitas ringan, sedang, dan berat. ${ }^{3}$

Practice guidelines for acute pain management in the perioperative setting yang diperbaharui tahun 2012 oleh American Society of Anesthesiologists (ASA) dinyatakan bahwa penggunaan acetaminophen, non steroidal anti inflammatory drugs (NSAID), COXIB dapat dijadikan pertimbangan untuk pengelolaan nyeri akut pascabedah sebagai bagian dari konsep analgesia multimodal. Obat-obat tersebut sebagai regimen tunggal mungkin tidak mencukupi untuk mengobati nyeri berat (severe), tetapi obat tersebut dapat dikombinasikan dengan opioid dan dapat menurunkan kebutuhan dosis opioid sehingga kemungkinan muncul efek samping opioid dapat diturunkan. ${ }^{4,5}$

Tramadol merupakan analgetik opioid sintetik yang diindikasikan untuk mengobati nyeri sedang yang bersifat akut. Lebih dari 90 negara di dunia sudah memakai obat ini sebagai analgetik, namun penggunaan tramadol juga mengakibatkan efek samping antara lain adalah mual muntah. Tramadol merupakan analgetik yang bekerja di sentral walaupun mekanisme kerja secara pasti masih belum jelas. Tramadol memiliki afinitas moderat pada reseptor $\mu$ dan lemah pada reseptor kappa dan delta, tetapi afinitasnya 5 sampai 10x kurang poten dibanding dengan morfin. Efek agonis opioid terhadap reseptor $\mu$, yaitu bahwa tramadol bekerja memperkuat efek menghambat nyeri di spinal descending inhibitory pathway dengan cara menghambat ambilan neuronal dari norepinefrin dan serotonin. ${ }^{6}$

Parasetamol adalah analgetik nonopioid dan nonsalisilat yang sudah digunakan lebih dari 40 tahun untuk mengatasi nyeri ringan sampai sedang. Parasetamol bekerja dengan meningkatkan batas ambang nyeri dengan cara menghambat $N$-metil-D-aspartate (NMDA) atau disebut substansi P serta prostaglandin $\mathrm{E}$ di sentral. Parasetamol memiliki efek analgesia dan juga antipiretik tanpa efek anti-inflamasi, aman digunakan, efek samping minimal, dan ditoleransi dengan baik. ${ }^{7}$ Parasetamol juga memiliki efek opioid-sparing bila digunakan bersama dengan opioid dosis rendah sehingga memberikan efek analgesia yang baik dengan meminimalkan efek samping opioid seperti depresi napas, bradikardia, dan hipoksia. ${ }^{8}$

Penelitian yang dilaksanakan pada tahun 2017 mengenai perbandingan pemberian tramadol intravena dosis tunggal dengan kombinasi tramadol dan parasetamol untuk nyeri pascaoperasi abdomen pada anak menunjukkan perbedaan intensitas nyeri yang signifikan selama 24 jam pertama. ${ }^{9}$ Demikian juga penelitian yang dilakukan tahun 2016 tentang evaluasi efikasi analgetik dan keamanan kombinasi deksketoprofen 25 mg dan tramadol $75 \mathrm{mg}$ dibanding dengan deksketoprofen $25 \mathrm{mg}$ dan tramadol 100 mg pada nyeri akut sedang sampai berat setelah operasi total artroplasti panggul. Hasil penelitian ini menegaskan keunggulan kombinasi deksketoprofen/tramadol atas terapi tunggal, bahkan pada dosis tramadol yang lebih tinggi. ${ }^{10}$

Penelitian tersebut di atas merupakan dasar penelitian ini, namun dari seluruh penelitian yang dipublikasikan belum pernah 
dibandingkan analgesia kombinasi tramadol $50 \mathrm{mg}$ intravena dan parasetamol $1.000 \mathrm{mg}$ intravena dengan kombinasi tramadol 50 mg intravena dan deksketoprofen $50 \mathrm{mg}$ intravena terhadap intensitas nyeri dan kadar $\mathrm{PGE}_{2}$ pascabedah ortopedi ekstremitas bawah.

Tujuan penelitian ini adalah mengetahui perbandingan pengaruh pemberian analgesia kombinasi tramadol 50 mg dan deksketoprofen $50 \mathrm{mg}$ intravena dengan kombinasi tramadol $50 \mathrm{mg}$ dan parasetamol $1.000 \mathrm{mg}$ intravena terhadap intensitas nyeri dan kadar $\mathrm{PGE}_{2}$ pada pasien pascabedah ortopedi ekstremitas bawah.

\section{Subjek dan Metode}

Penelitian ini merupakan uji klinis rancangan acak tersamar ganda. Jumlah sampel pada penelitian ini menggunakan uji hipotesis terhadap rerata 2 populasi untuk dua kelompok independen didapatkan hasil $\mathrm{n}=46$ orang yang dibagi menjadi 23 orang per kelompok. Pada kedua kelompok diberikan premedikasi alprazolam 0,5 mg (malam hari sebelum operasi), kemudian dilakukan anestesi regional subarachnoid block (SAB) dengan menggunakan agen bupivakain $0,5 \%$ $10 \mathrm{mg}$ ditambah fentanil $25 \mathrm{mcg}$ sebagai adjuvan. Kelompok $\mathrm{P}$ yang mendapatkan analgetik pascaooperasi tramadol $50 \mathrm{mg}$ dan parasetamol $1.000 \mathrm{mg}$ intravena setiap 8 jam, kelompok D mendapatkan analgetik tramadol $50 \mathrm{mg}$ dan deksketoprofen $50 \mathrm{mg}$ intravena setiap 8 jam. Penilaian NRS dilakukan 8 dan 16 jam setelah operasi. Pengukuran $\mathrm{PGE}_{2}$ dilakukan pada 8 jam setelah T0 $\mathrm{PGE}_{2}$ (T1 $\mathrm{PGE}_{2}$ ) dan 8 jam setelah T1 $\mathrm{PGE}_{2}\left(\mathrm{~T} 2 \mathrm{PGE}_{2}\right.$ ). Kebutuhan rescue analgetik, efek samping, dan tanda vital dicatat selama observasi. Data dianalisis dengan Uji Fisher Exact, Mann Whitney $U$ menggunakan kriteria $\mathrm{p} \geq 0,05$.

Subjek penelitian adalah pasien yang menjalani prosedur pembedahan elektif ortopedi ekstremitas bawah di ruangan bedah sentral RSUP Dr. Wahidin Sudirohusodo dan atau Rumah Sakit Jejaring di Makassar pada bulan Juli-September 2018 yang memenuhi kriteria inklusi. Kriteria inklusi adalah pasien yang menjalani pembedahan elektif orthopedi ekstremitas bawah dengan teknik subarachnoid block (SAB), status fisik American Society of Anesthesiologist (ASA) kelas 1-2, usia 18-65 tahun, body mass index (BMI) 18,50$24,99 \mathrm{~kg} / \mathrm{cm}^{2}$, operasi kurang dari $3 \mathrm{jam}$, dan ada persetujuan dari dokter ortopedi yang merawatnya. Penelitian ini telah disetujui oleh Komisi Etik Penelitian Biomedis pada manusia Fakultas Kedokteran Universitas Hasanuddin.

Kriteria eksklusi penelitian adalah terdapat kontraindikasi tindakan anestesi regional, riwayat alergi terhadap obat yang digunakan, menderita penyakit kardiovaskular, penyakit hepar dan penyakit ginjal, sedang hamil, mendapat terapi opioid dan obat antiinflamasi sebelumnya, serta pasien yang mendapatkan kemoterapi.

Kriteria pengeluaran apabila selama operasi terjadi efek samping yang hebat, perdarahan melebihi maximum allowed blood loss (MABL) atau mendapatkan tranfusi darah intra dan pascaoperasi, pasien/keluarga mengundurkan diri, timbul kompikasi pembedahan, dan dibutuhkan konversi ke teknik anestesi umum.

\section{Hasil}

Tabel 1 menunjukkan deskripsi sampel berdasar atas jenis kelamin, ASA PS, usia, dan body mass index (BMI). Pada kelompok deksketoprofen terdapat 13 orang laki-laki dan 10 orang perempuan. Pada kelompok deksketoprofen juga terdapat sampel dengan ASA PS I, yaitu 9 orang dan ASA PS II sebanyak 14 orang. Pada kelompok parasetamol terdapat 11 orang laki-laki dan 12 orang perempuan. Pada kelompok parasetamol juga terdapat sampel dengan ASA PS I, yaitu 10 orang dan ASA PS II sebanyak 13 orang. Kedua kelompok diuji dengan uji homogenitas Fisher's exact didapatkan $\mathrm{p}>0,05$ yang berarti sampel tersebut homogen secara statistik.

Tabel 1 juga menunjukkan bahwa tidak ditemukan perbedaan usia yang bermakna antara kelompok deksketoprofen dan kelompok parasetamol $(\mathrm{p} \geq 0,05)$. Begitu pula untuk BMI, tidak ditemukan perbedaan yang bermakna $(p \geq 0,05)$. Dilakukan analisis 
Tabel 1 Karakteristik Sampel berdasar Jenis Kelamin, ASA PS, Usia, dan IMT

\begin{tabular}{lccc}
\hline \multicolumn{1}{c}{ Karakteristik Sampel } & $\begin{array}{c}\text { Tramadol + } \\
\text { Deksketoprofen } \\
\mathbf{n = 2 3}\end{array}$ & $\begin{array}{c}\text { Tramadol + Parasetamol } \\
\mathbf{n = 2 3}\end{array}$ & $\mathbf{p}$ \\
\hline $\begin{array}{l}\text { Jenis kelamin } \\
\text { Laki-laki }\end{array}$ & 13 & 11 & $0,768^{*}$ \\
$\quad$ Perempuan & 10 & 12 & \\
ASA PS & & & $1,00^{*}$ \\
1 & 9 & 10 & \\
2 & 14 & 13 & $0,785^{* *}$ \\
Usia (tahun), Rerata \pm SD & $36,13 \pm 14,01$ & $37,35 \pm 15,96$ & $0,248^{* *}$ \\
IMT $\left(\mathrm{kg} / \mathrm{m}^{2}\right)$, Rerata \pm SD & $22,55 \pm 1,87$ & $21,89 \pm 1,96$ & \\
\hline
\end{tabular}

Keterangan: *dianalisis dengan uji homogenitas Fisher's exact ( $\mathrm{p}>0,05)$

**diuji dengan analisis one way ANOVA $(\mathrm{p}>0,05)$

uji beda rerata dengan independent t-test didapatkan bahwa sampel kedua kelompok bersifat homogen.

Nilai rerata NRS T1 (8 jam pascaoperasi) dan NRS T2 (16 jam pascaoperasi) pada kelompok tramadol dan deksketoprofen lebih rendah dibanding dengan kelompok tramadol dan parasetamol. Nilai rerata kedua kelompok tersebut berdasar analisis statistik menggunakan uji-t berpasangan didapatkan perbedaan yang bermakna $(\mathrm{p}<0,05$; Tabel 2 ; Gambar 1).

Analisis rerata kadar $\mathrm{PGE}_{2}$ antara T0 dan T1 pada kelompok deksketoprofen menggunakan uji-t berpasangan tidak didapatkan $p=$ 0,062 , ini menunjukkan tidak ada perbedaan bermakna secara statistik ( $>0,05$; Tabel 3). Pada kelompok deksketoprofen juga didapatkan penurunan kadar rerata $\mathrm{PGE}_{2}$ antara T0 dan T2 serta antara T1 dan T2 dengan perbedaan bermakna $(\mathrm{p}<0,05$; Tabel 3; Gambar 2).

Pada kelompok parasetamol didapatkan rerata kadar $\mathrm{PGE}_{2}$ antara $\mathrm{T} 0$ dan $\mathrm{T} 1, \mathrm{~T} 0$ dan $\mathrm{T} 2$, serta antara $\mathrm{T} 1$ dan $\mathrm{T} 2$ tidak berbeda bermakna secara statistik $(p>0,05$; Tabel 3 ; Gambar 2).

Pada penelitian ini tidak ditemukan efek samping depresi napas, muntah, hipotensi dan alergi obat pada kedua kelompok sampel. Efek samping yang ditemukan hanya mual, yaitu pada waktu 8 jam pascabedah yang ditemukan pada seorang dari kelompok deksketoprofen, sedangkan tidak terjadi komplikasi mual pada kelompok parasetamol. Perbandingan kejadian komplikasi pada kedua kelompok ini diuji dengan Uji Mann-Whitney $U$ dengan hasil yang tidak bermakna secara statistik $(p>0,05)$.

\section{Pembahasan}

Penelitian ini dilakukan terhadap 46 orang pasien yang menjalani operasi ortopedi ekstremitas bawah di Rumah Sakit Wahidin Sudirohusodo Makassar dan Rumah sakit jejaring periode bulan Agustus-September

Tabel 2 Perbandingan NRS berdasar Waktu antara Kedua Kelompok

\begin{tabular}{lccc}
\hline \multirow{2}{*}{ NRS } & Tramadol+Deksketoprofen & Tramadol+Parasetamol & \multirow{2}{*}{ Nilai p } \\
\cline { 2 - 3 } & Rerata \pm SD & Rerata \pm SD & $0,049^{*}$ \\
T1 $(8$ jam $)$ & $1,74 \pm 0,541$ & $2,22 \pm 0,998$ & $0,035^{*}$ \\
\hline
\end{tabular}

Keterangan: data numerik disajikan sebagai rerata dan standar deviasi (SD) *: dianalisis dengan uji-t berpasangan $(\mathrm{p}<0,05)$ 


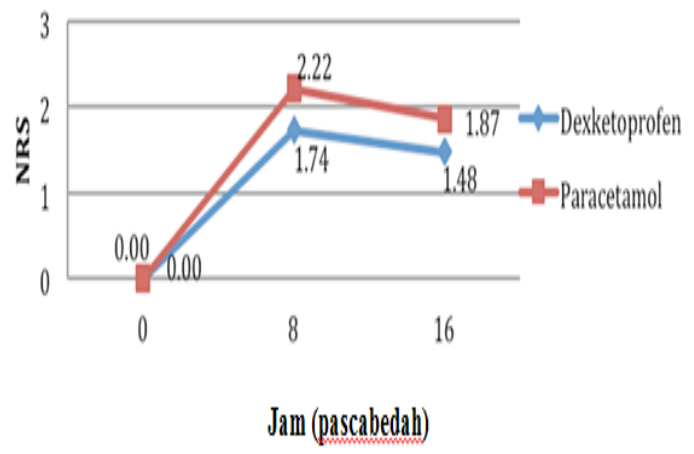

Gambar 1 Perbandingan NRS berdasar Waktu Kelompok Tramadol dan Deksketoprofen dengan Kelompok Tramadol dan Parasetamol

2018. Subjek terbagi dalam 2 kelompok, yaitu kelompok tramadol dan deksketoprofen sebanyak 23 orang serta kelompok tramadol dan parasetamol sebanyak 23 orang yang memenuhi kriteria inklusi.

Pada penelitian ini tidak didapatkan perbedaan bermakna antara kedua kelompok menurut variabel jenis kelamin, usia, BMI dan ASA PS, sehingga karakterisitik sampel dapat dinyatakan homogen secara statistik.

Pengelolaan nyeri pascabedah sebaiknya ditujukan ke arah pencegahan (preventif analgesia) atau dapat meminimalkan terjadi proses sensitisasi nyeri. Nyeri kronik yang persisten dapat terjadi pada $10-50 \%$ kasus yang tidak mendapat analgetik pascabedah adekuat. Prinsip analgesia preventif ini

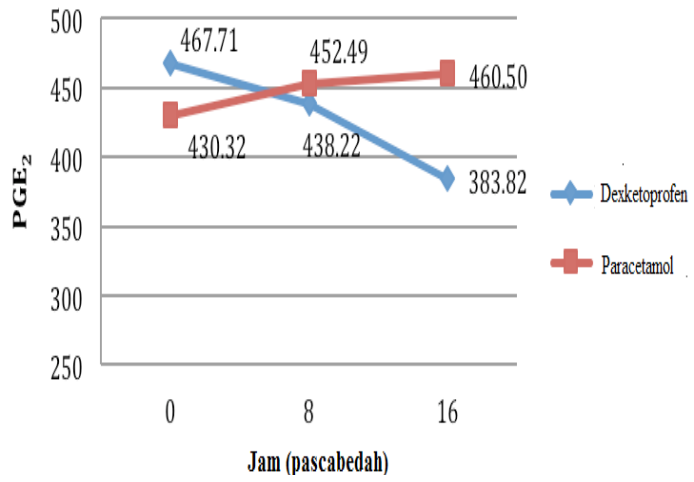

Gambar 2 Perbandingan Kadar PGE $_{2}$ Dua Kelompok Tramadol dan Dexketoprofen dengan Kelompok Tramadol dan Paracetamol

berdasar atas asumsi bahwa satu-satunya cara untuk mencegah sensitisasi sentral adalah memblokade sinyal nyeri apapun dari luka pembedahan, mulai dari saat insisi hingga penyembuhan luka sempurna. Pemberian analgetik sebelum nyeri itu timbul dan pascabedah diharapkan dapat mengurangi intensitas dan durasi nyeri pada nyeri akut pascabedah yang pada akhirnya mencegah timbul nyeri persisten.

Nilai rerata NRS T1 (8 jam pascabedah) dan NRS T2 (16 jam pascabedah) pada kelompok tramadol dan deksketoprofen lebih rendah dibanding dengan nilai rerata NRS kelompok tramadol dan parasetamol dengan perbedaan yang bermakna secara statistik $(p<0,05$; Tabel 2).

Tabel 3 Perubahan Prostaglandin $\mathrm{E}_{2}\left(\mathrm{PGE}_{2}\right)$ pada Tiap-tiap Kelompok

\begin{tabular}{ccccc}
\hline \multirow{2}{*}{ Kelompok } & \multicolumn{3}{c}{ Kadar PGE (Mean \pm SD) } & \multirow{2}{*}{ p $^{*}$} \\
\cline { 2 - 4 } & $467,71 \pm 163,820$ & $438,22 \pm 158,53$ & & 0,062 \\
Tramadol + deksketoprofen & $467,71 \pm 163,820$ & & $383,82 \pm 193,83$ & $0,009^{*}$ \\
& & $438,22 \pm 158,53$ & $383,82 \pm 193,83$ & $0,010^{*}$ \\
Tramadol + parasetamol & $430,32 \pm 90,885$ & $452,49 \pm 123,53$ & & 0,291 \\
& $430,32 \pm 90,885$ & & $460,5 \pm 122,536$ & 0,706 \\
& & $452,49 \pm 123,53$ & $460,5 \pm 122,536$ & 0,227 \\
\hline
\end{tabular}

Keterangan: data disajikan dalam bentuk mean \pm SD, *: dianalisis dengan uji-t berpasangan, $\mathrm{p}<0,05$ dianggap bermakna secara statistik 
Keadaan ini sesuai dengan penelitian yang dilakukan pada tahun 2006 yang membandingkan pemberian deksketoprofen $25 \mathrm{mg} /$ oral, ketoprofen $50 \mathrm{mg} /$ oral, serta parasetamol $500 \mathrm{mg} /$ oral dengan rescue tramadol $50 \mathrm{mg} /$ oral. Pada penelitian ini didapatkan bahwa pasien yang menerima dekskeprofen $25 \mathrm{mg} /$ oral memberikan nilai NRS yang lebih kecil yang dibuktikan dengan lebih sedikitnya jumlah konsumsi tramadol 50 $\mathrm{mg} /$ oral sebagai rescue.

Penelitian lain yang dilakukan tahun 2017 tentang perbandingan pemberian tramadol intravena dosis tunggal dengan kombinasi tramadol serta parasetamol untuk nyeri pascaoperasi setelah bedah abdomen pada anak menunjukkan perbedaan yang signifikan terhadap intensitas nyeri selama 24 jam pertama. Penelitian ini merekomendasikan penggunaan infus tramadol dalam dosis 0,25 $\mathrm{mg} / \mathrm{kgBB} / \mathrm{jam}$ dalam 24 jam pertama setelah operasi dengan kombinasi parasetamol per rektal dalam dosis harian $90 \mathrm{mg} / \mathrm{kgBB} / \mathrm{hari}$ dalam empat dosis terbagi untuk anak. ${ }^{9}$

Penilaian NRS serta tambahan kebutuhan analgetik itu dinyatakan sebanding antara kedua kelompok ini, walaupun terdapat perbedaan cara kerja antara parasetamol dan deksketoprofen. Kelebihan parasetamol bekerja di sentral dan perifer, sedangkan deksketoprofen bekerja hanya di perifer. Namun, parasetamol tidak mempunyai efek anti-inflamasi seperti efek yang dimiliki oleh deksketoprofen. ${ }^{11}$

Kerusakan jaringan akan mengakibatkan dikeluarkan asam arakidonat yang selanjutnya akan diubah menjadi leukotriene oleh enzim lipoksigenase dan lalu diubah menjadi prostaglandin oleh enzim sikloksigenase. Obat anti-inflamasi nonsteroid atau OAINS mampu mengurangi peradangan yang bekerja dengan mengurangi produksi prostaglandin. Prostaglandin adalah bahan kimia yang menyebabkan inflamasi, nyeri, dan demam. Prostaglandin juga mampu melindungi lapisan lambung dan usus dari efek kerusakan akibat asam lambung, menyebabkan pembekuan darah dengan mengaktifkan trombosit darah, dan memelihara fungsi normal ginjal. OAINS menghambat aktivitas enzim COX-1 dan COX-2 yang membentuk prostaglandin.

Penelitian ini juga melakukan pengukuran kadar prostaglandin pada kedua kelompok. Pada kelompok deksketoprofen didapatkan penurunan rerata kadar $\mathrm{PGE}_{2}$ T0 $(467,71 \pm 163,820)$ dan T1 $(438,22 \pm 158,53)$. Namun, analisis data menggunakan uji-t berpasangan tidak ada perbedaan bermakna secara statistik ( $p>0,05$; Tabel 3 ).

Pada kelompok deksketoprofen itu juga didapatkan penurunan kadar rerata $\mathrm{PGE}_{2}$ antara $\mathrm{T} 0$ dan $\mathrm{T} 2$, serta $\mathrm{T} 2$ dan $\mathrm{T} 1$ dengan perbedaan bermakna secara statistik $(p<0,05$; Tabel 3).

Budaya hasil tersebut terjadi penurunan prostaglandin secara bermakna setelah 8 jam kedua dan hal ini dapat dijelaskan bahwa deksketoprofen adalah garam trometamin yang sangat larut dalam air dan merupakan dextrorotary enantiomer murni dari racemic (RAC) ketoprofen yang mampu menghambat pembentukan prostaglandin dengan cara menghambat COX 1 dan COX 2 secara seimbang (equipotent). Kerusakan jaringan itu akan menyebabkan pengeluaran asam arakidonat yang selanjutnya diubah menjadi leukotriene oleh enzim lipoksigenase dan asam arakidonat juga diubah menjadi prostaglandin oleh enzim sikloksigenase. Obat anti-inflamasi nonsteroid (OAINS) memiliki efek mengurangi peradangan, tetapi efek tersebut tidak sama kuatnya dengan obat steroid yang juga memberikan efek mengurangi peradangan. ${ }^{12}$

Pada kelompok parasetamol didapatkan peningkatan rerata kadar $\mathrm{PGE}_{2}$ antara T0 $(430,32 \pm 90,885)$ dan T1 $(452,49 \pm 123,53)$. Namun, berdasar analisis uj-t berpasangan tidak didapatkan perbedaan yang bermakna secara statistik. Pada kelompok parasetamol juga didapatkan peningkatan kadar rerata $\mathrm{PGE}_{2}$ antara T0 dan T2 serta antara T1 dan T2 dengan perbedaan tidak bermakna secara statistik ( $p>0,05$; Tabel 3).

Hasil penelitian ini sesuai dengan hasil penelitian tahun 2013 yang menyatakan bahwa ibuprofen yang termasuk dalam salah satu obat golongan NSAID yang terbukti lebih menekan kadar $\mathrm{PGE}_{2}$ pada gingival crevicular 
fluid (GCF) selama operasi gigi ortodontik. ${ }^{13}$

Pengukuran kadar prostaglandin pada kelompok parasetamol didapatkan kadar prostaglandin itu meningkat, tetapi tidak bermakna. Hal ini sesuai dengan penjelasan sebelumnya bahwa parasetamol adalah inhibitor lemah sintesis PG dari COX-1 dan COX-2 dalam sistem sel yang rusak, tetapi, sebaliknya, konsentrasi terapeutik parasetamol menghambat sintesis PG dalam sel utuh secara in vitro ketika tingkat substrat asam arakidonat rendah (kurang dari sekitar $5 \mathrm{mmol} / \mathrm{L})$. Ketika kadar asam arakidonat rendah, PG sebagian besar disintesis oleh COX2 dalam sel yang mengandung COX-1 dan COX2. Dengan demikian, selektivitas parasetamol mungkin karena penghambatan jalur COX-2 yang berlangsung pada tingkat rendah.

Hipotesis ini konsisten dengan efek farmakologi yang serupa dari parasetamol dan inhibitor COX-2 selektif. Parasetamol diduga merupakan COX-3 adalah variasi dari COX-1 yang diduga menjadi mekanisme aksi parasetamol. Ada bukti yang cukup kuat bahwa efek analgesik parasetamol bersifat sentral karena aktivasi jalur serotonergik yang menurun, tetapi cara kerja utamanya mungkin masih menghambat sintesis PG.

Peran parasetamol pada tingkat molekuler tidak jelas, tetapi dapat dikaitkan dengan produksi metabolit reaktif oleh fungsi peroksidase COX-2 yang dapat menghabiskan glutation, yang merupakan kofaktor enzim seperti PGE synthase. ${ }^{14,15}$

Tidak seperti NSAID yang bertindak pada COX-1 dan -2, parasetamol dapat bertindak pada varian hambatan COX-1 (awalnya dianggap isoenzim berbeda, COX-3). Varian COX-1 ini dianggap aktif dalam sistem saraf pusat, bukan di tempat jaringan yang terluka atau meradang sehingga penghambatan oleh parasetamol di sini akan menjelaskan kurangnya aktivitas anti-inflamasi dan antiplatelet, sementara masih memberikan sifat analgesik dan antipiretik yang sangat efektif. ${ }^{16}$ Pada penelitian ini tidak ditemukan efek samping depresi muntah, hipotensi, dan alergi obat pada kedua kelompok sampel. Efek samping yang ditemukan hanya mual, yaitu pada waktu 8 jam pascabedah.

Pada penelitian ini kejadian komplikasi mual pada kelompok deksketoprofen terjadi pada seorang, sedangkan tidak terjadi komplikasi mual pada kelompok parasetamol. Perbandingan kejadian komplikasi pada kedua kelompok ini diuji dengan Uji Mann-Whitney $\mathrm{U}$ dan dinilai tidak bermakna secara statistik ( $p>0,05)$. Kejadian mual pada penelitian ini dapat diakibatkan oleh pemberian tramadol yang mempunyai efek samping tersebut, jadi tidak memberikan pengaruh hasil penelitian karena kedua kelompok mempergunakan tramadol.

Untuk meneliti efek samping obat membutuhkan perhitungan jumlah sampel yang lebih besar. Jadi, hasil efek samping obat pada penelitian ini belum dapat disimpulkan.

Dibutuhkan penelitian lebih lanjut efek samping obat dengan jumlah sampel yang lebih besar.

\section{Simpulan}

Intensitas nyeri kelompok kombinasi analgesia tramadol $50 \mathrm{mg}$ dan deksketoprofen $50 \mathrm{mg}$ intravena lebih rendah dibanding dengan kombinasi tramadol $50 \mathrm{mg}$ dan parasetamol $1.000 \mathrm{mg}$. Kombinasi analgesia tramadol $50 \mathrm{mg}$ dan deksketoprofen $50 \mathrm{mg}$ intravena

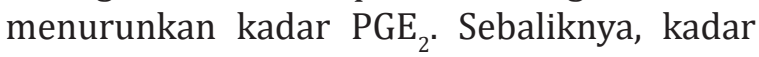
$\mathrm{PGE}_{2}$, meningkat pada kombinasi obat analgesia tramadol $50 \mathrm{mg}$ dan parasetamol $1.000 \mathrm{mg}$ intravena pascabedah ortopedi ekstremitas bawah.

\section{Daftar Pustaka}

1. Brandsborg B, Dueholm M, Jensen TS, Nikolajsen L. Mechanosensitivity before and after hysterecyomy a prospective study on the prediction of acute and chronic postoperative pain. Br J Anaesth. 2011;9:1-8.

2. Garimella V, Cellini C. Postoperative pain control. Clin Colon Rectal Surg. 2013;26(3);191-6.

3. Buvanendran A, Kroin JS. Multimodal analgesia for controlling acute 
postoperative pain. Curr Opin Anaesth 2009;22:588-93.

4. Brandsborg B, Dueholm M, Jensen TS, Nikolajsen L. Mechanosensitivity before and after hysterecyomy a prospective study on the prediction of acute and chronic postoperative pain. Br J Anaesth. 2011;9:1-8.

5. Chou R, Gordon DB, Casasola L, Rosenberg JM, Bickler S, Brennan T, dkk. Guideline on the management of postoperative pain. J Pain. 2016;17(2):137-57.

6. Sawaddiruk $\mathrm{P}$, Paiboonworachat $\mathrm{S}$, Janthawichai K. Comparison of efficacy and effectiveness between ultracet and tramadol/acetaminophen in acute postoperative pain after upper extremity surgery. J Med Assoc Thail. 2010;93(7):812-7.

7. Pergolizzi JV, van de Laar M, Langford R. Tramadol-paracetamol Fixed-dose combination in the treatment of moderate to severe pain. J Pain Res. 2012;5:327-46.

8. Vadivelu N, Mitra S, Narayan D. Review recent advances in postoperative pain management. Yale J Biol Med. 2010;83(1):11-25.

9. Ali S, Sofi K, Dar AQ. Comparison of intravenous infusion of tramadol alone with combination of tramadol and paracetamol for postoperative pain after major abdominal surgery in children. Anesth Essays Res. 2017;11(2):472-6.

10. McQuayHJ,MooreRA, BertaA, Gainutdinovs O, Fülesdi B, Porvaneckas N. Randomized clinical trial of dexketoprofen/tramadol $25 \mathrm{mg} / 75 \mathrm{mg}$ in moderate-to-severe pain after total hip arthroplasty. $\mathrm{Br} \mathrm{J}$ Anaesth. 2016;116(2):269-76.

11. Kesimci E, Gümüș T, Izdeș S, Sen P, Kanbak P. Comparison of efficacy of dexketoprofen versus paracetamol on postoperative pain and morphine consumption in laminectomy patients. Agri. 2011;23:1539.
12. Andrew M, Jodie B. Systemic review of dexketoprofen in acute and chronic pain. Biomed Cen Clin Phar. 2008;8(11):1-11.

13. Tunali Y, Akçil EF, Dilmen OK, Tutuncu AC, Koksal GM, Akbas S. Efficacy of intravenous paracetamol and dexketoprofen on postoperative pain and morphine consumption after a lumbar disk surgery. J Neurosurg Anesthesiol. 2013;25(2):143-7.

14. Graham GG, Davies MJ, Day RO, Mohamudally A, Scott KF. The modern pharmacology of paracetamol: therapeutic actions, mechanism of action, metabolism, toxicity and recent pharmacological findings. Inflammopharmacology. 2013;21 (3): 201-32.

15. Samad TA, Sapirstein AA, Woolf CJ. Prostanoid and pain unraveling mechanism and revealing therapetic targets. Trens Mol Med. 2012;8:390-6.

16. Kiliçaslan A, Tuncer S, Yüceaktaş A, Uyar M, Reisli R. The effects of intravenous paracetamol on postoperative analgesia and tramadol consumption in cesarean operations. Agri. 2010;22(1):7-12.

17. Moore RA, Gay-Escoda C, Figueiredo R, Tóth-Bagi Z, Dietrich T, Milleri S. Dexketoprofen/tramadol: randomised double-blind trial and confirmation of empirical theory of combination analgesics in acute pain. J Headache Pain. 2015;16:541-6.

18. Carli F, Baldini G. Perioperative pain management and enchanced outcomes. Dalam: Butterworth JF, Mackey DC, Wasnick JD, penyunting. Clinical anesthesilogy. Edisi ke-5. New York: McGraw-Hill; 2013. hlm. 1087-105.

19. Apfelbaun JL, Asburn MA, Connis RP, Gan TJ, Nickinovich DG. Practice guidelines for acute pain management in the perioperative setting. Anesthesiology. 2012;5(116):248-73. 